OPEN ACCESS

Edited by:

Jennifer Lee Jones,

Medical University of South Carolina,

United States

Reviewed by:

Anna Brancato,

University of Palermo, Italy

Umberto Volpe

Marche Polytechnic University, Italy

${ }^{*}$ Correspondence:

Anya Ragnhildstveit

anya.ragnhildstveit@utah.edu

Specialty section:

This article was submitted to

Psychopharmacology,

a section of the journal

Frontiers in Psychiatry

Received: 25 August 2021 Accepted: 27 October 2021 Published: 17 November 2021

Citation:

Ragnhildstveit A, Jackson LK Cunningham S, Good L, Tanner Q, Roughan $M$ and Henrie-Barrus $P$ (2021) Case Report: Unexpected

Remission From Extreme and Enduring Bulimia Nervosa With

Repeated Ketamine Assisted Psychotherapy.

Front. Psychiatry 12:764112.

doi: 10.3389/fpsyt.2021.764112

\section{Case Report: Unexpected Remission From Extreme and Enduring Bulimia Nervosa With Repeated Ketamine Assisted Psychotherapy}

\author{
Anya Ragnhildstveit ${ }^{1 *}$, Laura Kate Jackson ${ }^{1}$, Sarah Cunningham ${ }^{1}$, Linda Good ${ }^{2}$, \\ Quinn Tanner ${ }^{3}$, Matthew Roughan ${ }^{4,5}$ and Patricia Henrie-Barrus ${ }^{5,6}$ \\ ${ }^{1}$ Department of Psychology, University of Utah, Salt Lake City, UT, United States, ${ }^{2}$ Behavioral Science Department, Utah \\ Valley University, Orem, UT, United States, ${ }^{3}$ Division of Public Health, University of Utah School of Medicine, Salt Lake City, \\ UT, United States, ${ }^{4}$ Marriage and Family Therapy Program, Capella University, Minneapolis, MN, United States, ${ }^{5}$ Riverwoods \\ Behavioral Health, Provo, UT, United States, ${ }^{6}$ Department of Educational Psychology, University of Utah, Salt Lake City, \\ UT, United States
}

Background: Bulimia nervosa is a disabling psychiatric disorder that considerably impairs physical health, disrupts psychosocial functioning, and reduces overall quality of life. Despite available treatment, less than half of sufferers achieve recovery and approximately a third become chronically ill. Extreme and enduring cases are particularly resistant to first-line treatment, namely antidepressants and cognitive behavioral therapy, and have the highest rate of premature mortality. Here, we demonstrate that in such cases, repeated sessions of ketamine assisted psychotherapy (KAP) is an effective treatment alternative for improving symptoms.

Case Presentation: A 21-year-old woman presented with extreme and enduring bulimia nervosa. She reported recurrent binge-eating and purging by self-induced vomiting 40 episodes per day, which proved refractory to both pharmacological and behavioral treatment at the outpatient, residential, and inpatient level. Provided this, her physician recommended repeated KAP as an exploratory and off-label intervention for her eating disorder. The patient underwent three courses of KAP over 3 months, with each course consisting of six sessions scheduled twice weekly. She showed dramatic reductions in binge-eating and purging following the first course of treatment that continued with the second and third. Complete cessation of behavioral symptoms was achieved 3 months post-treatment. Her remission has sustained for over 1 year to date.

Conclusions: To our knowledge, this is the first report of repeated KAP used to treat bulimia nervosa that led to complete and sustained remission, a rare outcome for severe and enduring cases, let alone extreme ones. Additionally, it highlights the degree to which KAP can be tailored at the individual level based on symptom severity and treatment response. While its mechanism of action is unclear, repeated KAP is a promising intervention for bulimia nervosa that warrants future research and clinical practice consideration.

Keywords: bulimia nervosa, eating disorder, binge-eating, purging, ketamine, ketamine assisted psychotherapy, psychopharmacology, case report 


\section{INTRODUCTION}

Bulimia nervosa (BN) is a disabling psychiatric disorder characterized by recurrent binge-eating (consuming objectively large amounts of food with a sense of lost control) and inappropriate compensatory behaviors (self-induced vomiting; laxative, diuretic, or medication misuse; and fasting or excessive exercise) aimed at preventing weight gain $(1,2)$. Overtime, the severity of these patterns significantly disrupts physical health and psychosocial functioning, as well as impacts families and communities at large (3). Approximately 50 million people worldwide will develop BN at some point in their life (4). Moreover, studies have found BN to be associated with concomitant psychiatric comorbidity [e.g., mood disorders and substance abuse; $(5,6)]$ in addition to premature mortality due to medical complications (7-9). Death by suicide is also eight times more likely to occur among individuals with $\mathrm{BN}$ compared to the general population, with more than a third experiencing lifetime rates of non-suicidal self-injury $(10,11)$.

While pharmacological (e.g., selective serotonin reuptake inhibitors) and behavioral (e.g., cognitive behavioral therapy) interventions are effective in managing $\mathrm{BN}(12,13)$, many individuals do not respond to first-line treatment, are unsuccessful in later attempts, and fail to change over protracted periods $(14,15)$. Nearly $30 \%$ of sufferers become chronically ill as a result (16). For such chronic refractory cases, the paucity of evidence-based treatments has prompted paradigm shifts toward harm reduction and palliative care over recovery $(17,18)$.

Ketamine, a non-competitive N-methyl-D-aspartate receptor (NMDAr) antagonist, is an emerging therapy for treatmentresistant mood disorders $(19,20)$. Single-dose studies have consistently shown rapid antidepressant and anti-suicidal effects following ketamine treatment, though are relatively short-lived (1-4 weeks) (21-28). Ketamine assisted psychotherapy (KAP) has therefore been utilized to prolong ketamine's efficacy and maximize therapeutic outcomes (29-34). To date, few studies have used ketamine for the treatment of eating disorders, including one open-label study (35), two case reports $(36,37)$, and one longitudinal case series (38), all of which administered ketamine without a psychotherapeutic component. Nonetheless, the results are encouraging. Here, we report the case of a young woman suffering from extreme and enduring $\mathrm{BN}$, according to CARE (CAse REport) guidelines (39), who demonstrated remarkable symptom improvement following repeated sessions of KAP.

\section{CASE PRESENTATION}

A 21-year-old woman with $\mathrm{BN}$ of 9 years presented to the outpatient clinic, Forum Health. She was first diagnosed with $\mathrm{BN}$, binge-eating/purging type, at 12.5 years of age to which the severity of her symptoms steadily increased overtime. On

Abbreviations: BMI, body mass index; BN, bulimia nervosa; DSM-5, diagnostics and statistical manual of mental disorders, 5th edition; EDE-Q, eating disorder examination questionnaire; KAP, ketamine assisted psychotherapy; NMDAr, N-methyl-D-aspartate receptor; PBS, pseudo-bartter's syndrome. presentation, she reported alarming rates of binge-eating and purging by self-induced vomiting, averaging $\sim 40$ episodes per day for the last 12 months. Based on this frequency, her $\mathrm{BN}$ was categorized as "extreme" according to Diagnostic and Statistical Manual of Mental Disorders, Fifth Edition (DSM-5) criterion (14 or more episodes per week). Clinical assessment and scoring on the Eating Disorder Examination Questionnaire [EDE-Q; $(40,41)]$ additionally confirmed the severity of her illness. No laxative or diuretic abuse was reported. While not active in psychiatric treatment, the patient was taking potassium chloride $20 \mathrm{mEq}$ extended-release twice daily for hypokalemia as well as trazodone $100 \mathrm{mg}$ once daily in the evenings for sleep. At $161.92 \mathrm{~cm}$ tall and $46.26 \mathrm{~kg}$ in weight [body mass index (BMI) $=$ $17.6 \mathrm{~kg}$ per $\mathrm{m}^{2}$ ], the patient was amenorrheic and described body image disturbances, intense fear of gaining weight, and obsessivecompulsive tendencies around food (counting calories, binging by order of food group, and inability to discard uneaten items). She further displayed pronounced bilateral parotid sialadenosis (enlargement of the salivary glands) and pseudo-idiopathic edema, otherwise known as pseudo-bartter's syndrome (PBS): a rare and painful complication of $\mathrm{BN}$ characterized by hyperaldosteronism, metabolic alkalosis, and hypokalemia (42). As a University student studying cognitive neuroscience, the patient was obliged to take a medical leave due functional decline. "I lost all ability to take care of myself. I could not think clearly or show up for classes. I stopped socializing and running errands. I could hardly maintain basic hygiene."

Her psychiatric history included an adolescent sexual assault by a treating physician (13 years of age [2011]); a suicide attempt by cut throat injury at the level of the hyoid bone, which required emergency transportation and thyroid cartilage repair as well as inpatient hospitalization (13 years of age [2011]); a second suicide attempt by drug overdose involving mixed opioids, barbiturates, and antidepressants that resulted in emergency room hospitalization (15 years of age [2013]); and a blitz rape (surprise attack) by an unknown assailant (19 years of age [2017]). The patient's history also contained reports of major depression, general anxiety, and obsessive-compulsive disorder. There was no family history of eating disorders, including BN.

As an outpatient, she was treated with various pharmacotherapies (fluoxetine $40 \mathrm{mg}$ once daily, citalopram $20 \mathrm{mg}$ once daily, and naltrexone $50 \mathrm{mg}$ twice daily), behavioral interventions (cognitive behavioral therapy, mindfulnessbased stress reduction, and eye movement desensitization and reprocessing), and nutritional counseling (dietary modification and time-based feeding). She additionally was prescribed spironolactone $25 \mathrm{mg}$ twice daily, a potassium-sparing diuretic, on multiple occasions to treat PBS following attempts at purging cessation. However, the patient's binge-purge patterns continued. Finally, she received inpatient, residential, and intensive-outpatient eating disorder care (15-16 years of age [2013-2014]), which the patient described as a "traumatic experience" that resulted in immediate relapse upon discharge.

"My parents pulled me out of class and dropped me off at a center, leaving me there for almost 10 months. It was like being in prison. I was completely cut off from my friends and family. I was forced to eat unreasonable amounts of food at each meal. 


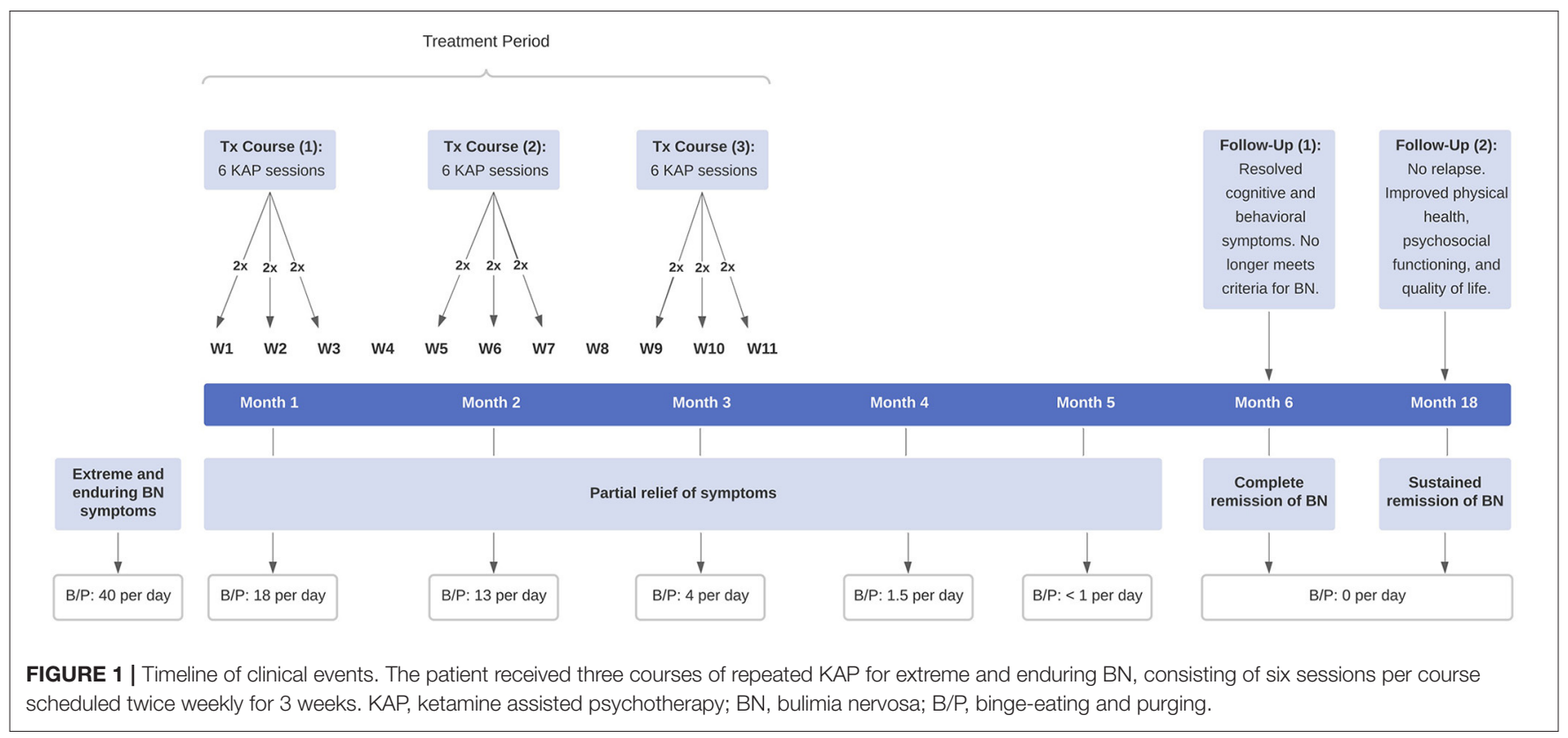

And I learned new [eating disorder] tricks from other patients that I tried later on. It was not a place conducive to recovery, at least for me. It just made my condition worse."

Her medical history detailed emergency room hospitalizations for hypokalemia $(16,19$, and 20 years of age $[2014,2017,2018])$, gastroesophageal reflux disorder (17-21 years of age [20152019]), gastric and duodenal ulcers ( 19 and 21 years of age [2017, 2019]), hypothyroidism (20-21 years of age [2018-2019]), and adrenocortical insufficiency (20-21 years of age [2018-2019]). Porcelain-laminate veneers were also placed on 10 of her teeth due to dental caries and enamel erosion from chronic purging (21 years of age [2019]).

Given the patient's extreme and chronic refractory state, her physician recommended repeated KAP, with the understanding it constituted an exploratory and off-label intervention for her eating disorder. She consented to treatment following a comprehensive medical evaluation and in-depth review of the procedures, risks, and possible side effects. A signed consent form was obtained. Prior to treatment, she met with a clinical psychologist to establish rapport and therapeutic alliance. The patient then underwent one course of repeated KAP, consisting of six sessions scheduled twice weekly for 3 weeks, with a minimum interval between sessions of $48 \mathrm{~h}$ (Figure 1). Each KAP session involved guided psychotherapy combined with racemic ketamine hydrochloride $(0.5 \mathrm{mg}$ per $\mathrm{kg}$ bodyweight suspended in $0.9 \%$ normal saline) administered intravenously over $40 \mathrm{~min}$. The drug regimen was standard practice in the clinic for sub-anesthetic ketamine infusions, which is most commonly used for treating psychiatric disorders and is supported by a substantial body of literature $(43,44)$. A person-centered, humanistic approach to psychotherapy was employed to facilitate the process of self-actualization and therapeutic change. KAP sessions were preceded by $30 \mathrm{~min}$ of preparatory psychotherapy and delivered in a private room with dimmed lights, ambient music, and textile art on the ceiling. The intervention components and ketamine regimen remained the same for all five consecutive sessions; and blood pressure, heart rate, and oxygen saturation were continuously monitored. Due to the severity of her eating disorder, however, the patient returned to the clinic 1 month later for a second course of repeated KAP and then again 1 month later for a third.

Dissociation, ego dissolution, and perceptual distortions were present during all KAP sessions, as evidenced by the patient's description of "being disconnected from reality," "losing [her] sense of identity and self", and "seeing abstract geometric patterns." She further exhibited mild diplopia (double vision), nystagmus (involuntary oscillations of the eyes), and alogia (lack of speech) during treatment that resolved completely. No other side effects or adverse events were reported. The patient's eating disorder symptoms remitted over the course of treatments, as measured by change in scoring on the EDE-Q as well as entries from a daily tracking log that recorded frequency of bingeeating and purging. On the EDE-Q, her global score dropped from 31.8 at baseline to 15.0 by the end of all three courses (18 sessions), with similar patterns recorded across all four subscales: "Restraint" ( $M=5.0, S D=2.2$ to $M=1.8, S D=1.3)$, "Eating Concern" ( $M=5.8, S D=0.5$ to $M=2.2, S D=1.5)$, "Weight Concern" ( $M=5.8, S D=0.5$ to $M=4.0, S D=1.9)$, and "Shape Concern" $(M=5.5, S D=0.8$ to $M=2.5, S D=$ 1.6) (Figure 2). Additionally, the patient's tracking log showed decreases in binge-eating and purging from 40 to 18 episodes per day after the first course of treatment (6 sessions), 18 to 13 episodes per day after the second course of treatment (12 sessions), and 13 to 4 episodes per day after the third course of treatment (18 sessions) (Figure 3).

Most notably, the patient stopped her binge-eating and purging behaviors 3 months post-treatment. Given her initial severity and chronic refractory state, this degree of improvement 


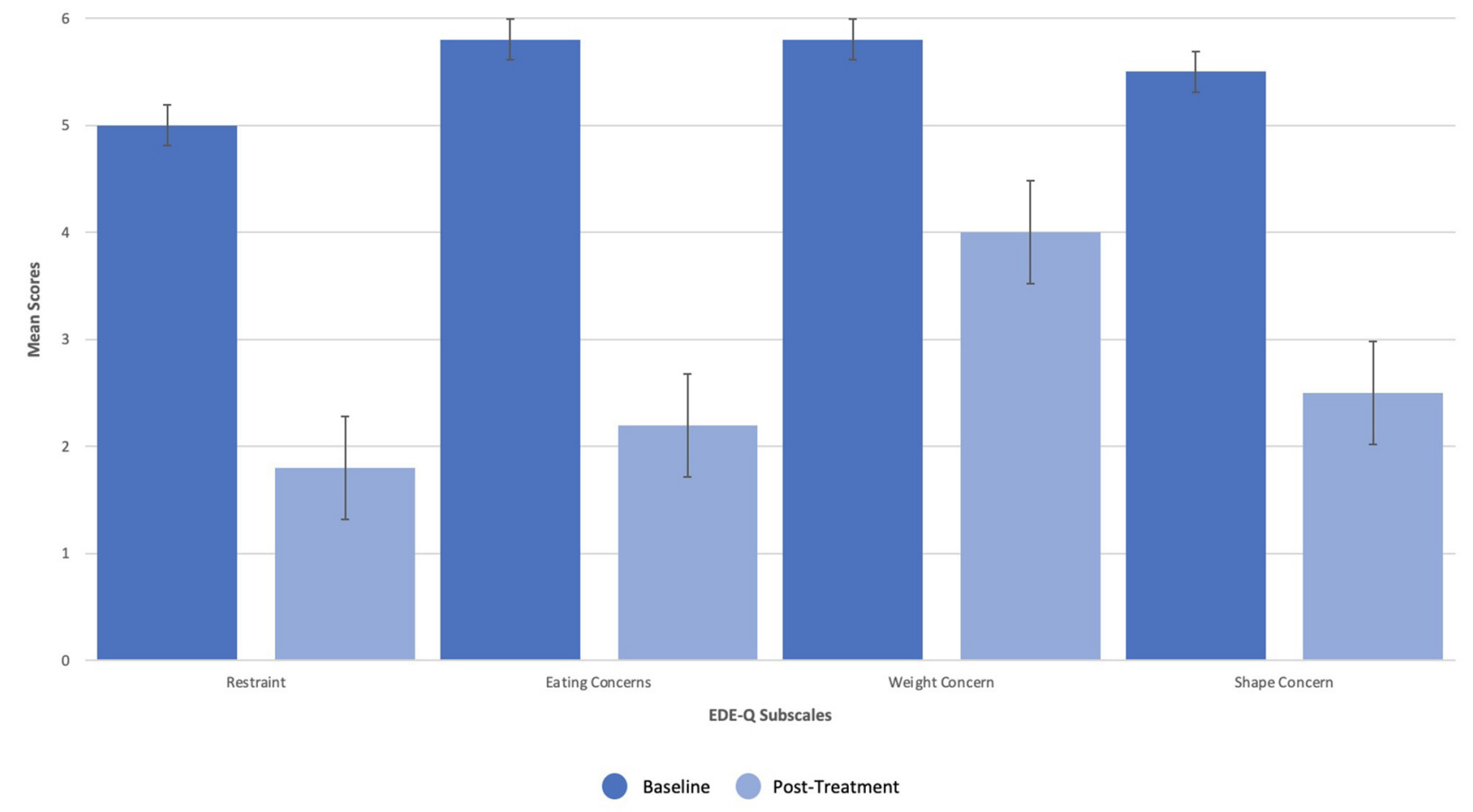

FIGURE 2 | Change in scoring on the Eating Disorder Examination Questionnaire (EDE-Q).

was striking. The patient's daily tracking log additionally showed no signs of relapse 1 year later, accompanied by marked improvement in psychosocial functioning. Specifically, she reported feeling "free" from intrusive BN thoughts and compulsions, "less impulsive" when faced with the urge to binge and purge, and "more confident" about her body in general. The patient has since resumed her academic studies in preparation for a doctoral program.

\section{DISCUSSION}

Severe, chronic, and refractory eating disorder symptoms are unfortunately common among patients with $\mathrm{BN}$. In this case, we describe a young woman with extreme and enduring $\mathrm{BN}$, who remained unresponsive to first-line treatment for nearly a decade, despite care at the outpatient, residential, and inpatient level. Her eating disorder was extreme, insofar as she engaged in recurrent binge-eating and purging by self-induced vomiting 40 episodes per day, which significantly exceeds DSM5 criterion (14 or more episodes per week). Given the severity of her illness, complete and sustained remission with three courses of repeated KAP (18 sessions) was both remarkable and unanticipated. These findings are more robust provided the patient was not active in psychiatric treatment for 1 year prior to clinic admission, excluding her long-standing prescription of potassium chloride for hypokalemia and trazodone for sleep. If ketamine and psychotherapy act synergistically, with therapy priming and enhancing the response to treatment, then its combined effect may explain the striking improvements in symptoms. Serial treatments likely account for the durability of response necessary for sustained remission, which is consistent with literature (45-48).

Provided this is the first report of repeated KAP used as an exploratory and off-label intervention for $\mathrm{BN}$, it is important to consider the a-priori context. Clinical recommendation to pursue repeated KAP was prompted by three factors. First, the patient's psychiatric and medical history that detailed unsuccessful treatment attempts, including pharmacotherapies, behavioral treatments, and nutritional counseling-even at higher levels of eating disorder care; and significant trauma to which accumulating evidence has shown ketamine to yield positive effects for (49-51). Second, her severe functional impairment in three major life domains, including academic work, social and family engagement, and personal responsibilities. The patient was binge-eating and purging nearly to the exclusion of all other activities, spending more time "alone in the bathroom than with [her] friends or family." Finally, an open-label case series on repeated ketamine in severe and enduring anorexia nervosa, showing modest improvements in eating disorder symptoms (38). 


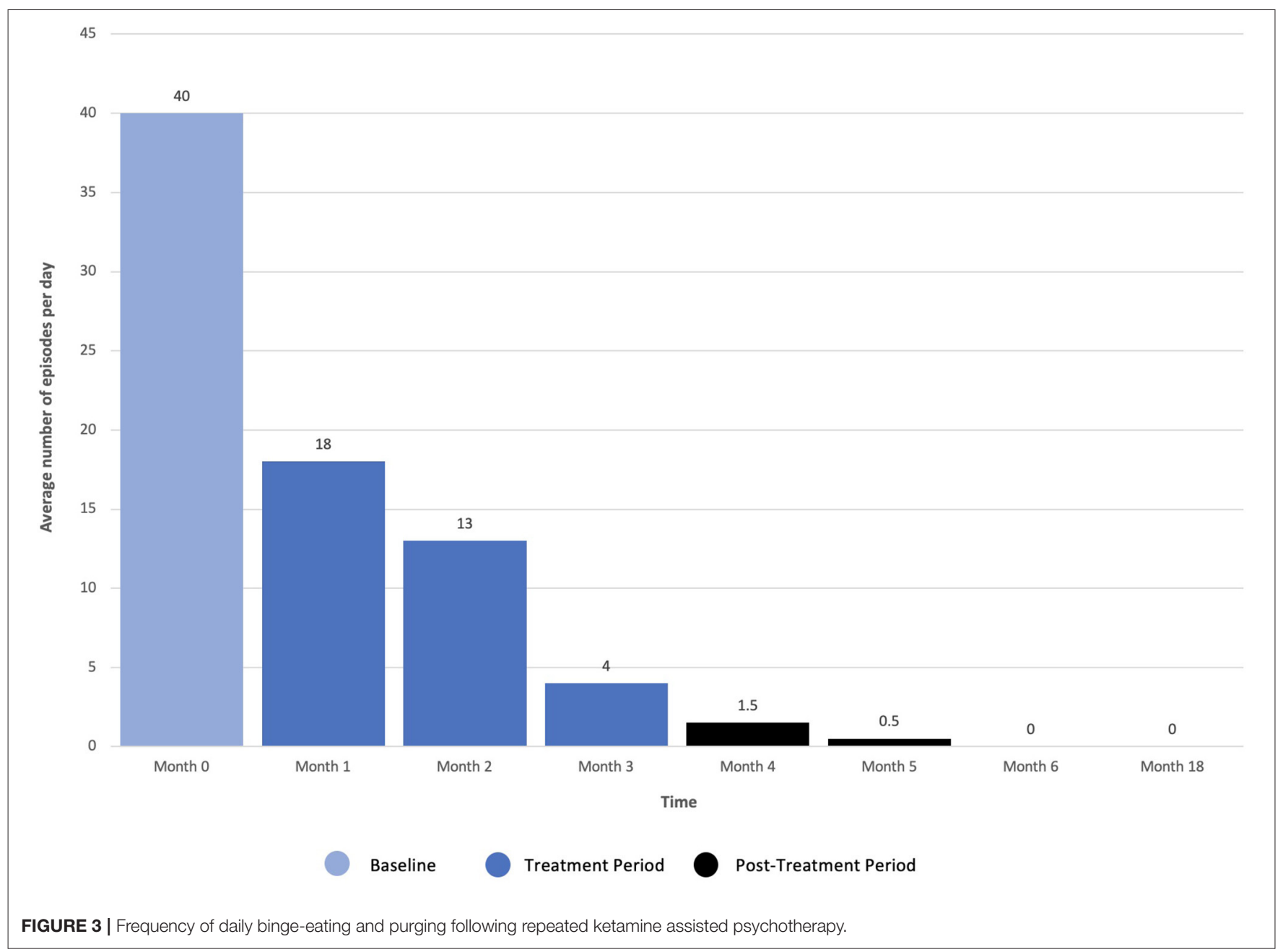

The patient's impetus for treatment was largely driven by fear of premature mortality-that if she did not attempt something new, she was going to "eat [herself] to death," quite literally. Serious degradation in the patient's physical and mental health status were particularly motivating. Apart from transient psychological (dissociation, ego dissolution, and perceptual distortions) and physiological (mild diplopia, nystagmus, and alogia) side effects of ketamine that resolved completely after each session, the treatment was well-tolerated. Following all three courses of treatment, the patient dramatically reduced her bingeeating and purging behaviors by $90 \%$ compared to baseline, as measured by the EDE-Q and daily tracking logs. She also demonstrated considerable improvements in disordered eating psychopathology that were captured by the subscales of the EDEQ, most notably "Restraint" (e.g., dietary rules and avoidance of food) and "Eating Concerns" (e.g., preoccupation with calories and fear of losing control over eating). Moreover, the patient regained control of her impulsive eating as well as resolved her obsessive-compulsive neurosis, which align with previous BNspecific findings from a study on intermittent ketamine infusions in eating disorders (35). At 3 months follow-up, she achieved complete cessation of binge-eating and purging and no longer met diagnostic criteria for $\mathrm{BN}$. The magnitude of response neither diminished over time, with no signs of relapse at 15 months follow-up, contrary to studies showing rapid decline of effects after treatment $(28,52,53)$. With sustained remission, the patient has adopted a healthier relationship with food, established psychosocial stability in her life, and resumed her academic studies in preparation for graduate school.

This is a single case report with inherent limitations in generalizing the findings to other patients with $\mathrm{BN}$. The lack of polypharmacy or medication washout is an additional limitation that may have unknowingly mediated improvements. Furthermore, it is unclear as to whether ketamine or psychotherapy produced greater clinical benefit, if both are coadjuvant and necessary, or if the treatment would have been as effective without psychotherapy and/or fewer sessions. Finally, a person-centered, humanistic approach to psychotherapy was employed, differing from more traditional methods, such as cognitive-behavioral, interpersonal, and psychodynamic therapy. Open pilot studies as well as fully-powered randomized controlled trials with longitudinal assessment are thus required to establish whether the outcome of this case can be replicated, to what degree ketamine and psychotherapy contribute to the 
overall success of the treatment, and the comparative efficacy of different psychotherapeutic interventions. Further research is also warranted to optimize KAP duration and frequency for this patient population.

\section{CONCLUSIONS}

This study provides compelling evidence that repeated KAP is an effective treatment for extreme and enduring $\mathrm{BN}$, which is exceedingly resistant to first-line therapies and associated with poor prognosis. It further highlights the utility of combined strategies that may prolong ketamine's efficacy, and subsequently maximize therapeutic outcomes at the individual level.

\section{DATA AVAILABILITY STATEMENT}

The original contributions presented in the study are included in the article/supplementary material, further inquiries can be directed to the corresponding author/s.

\section{ETHICS STATEMENT}

Ethical review and approval was not required for the study on human participants in accordance with the local legislation and

\section{REFERENCES}

1. American Psychiatric Association. Diagnostic and Statistical Manual of Mental Disorders: DSM-5. 5th ed. Washington DC: American Psychiatric Association (2013). doi: 10.1176/appi.books.9780890425596

2. Grilo CM, Ivezaj V, White MA. Evaluation of the DSM-5 severity indicator for bulimia nervosa. Behav Res Ther. (2015) 67:41-4. doi: 10.1016/j.brat.2015.02.002

3. van Hoeken D, Hoek HW. Review of the burden of eating disorders: mortality, disability, costs, quality of life, and family burden. Curr Opin Psychiatry. (2020) 33:521-7. doi: 10.1097/YCO.0000000000000641

4. Qian J, Wu Y, Liu F, Zhu Y, Jin H, Zhang H, et al. An update on the prevalence of eating disorders in the general population: a systematic review and meta-analysis. Eat Weight Disord. (2021) 1-4. doi: 10.1007/s40519-021-0 $1162-\mathrm{z}$

5. Himmerich H, Hotopf M, Shetty H, Schmidt U, Treasure J, Hayes RD, et al. Psychiatric comorbidity as a risk factor for the mortality of people with bulimia nervosa. Soc Psychiatry Psychiatr Epidemiol. (2019) 54:813-21. doi: 10.1007/s00127-019-01667-0

6. Dalle Grave R, Sartirana M, Calugi S. Complex Cases and Comorbidity in Eating Disorders: Assessment and Management. Springer Nature (2021). p. 7997. doi: 10.1007/978-3-030-69341-1

7. Arcelus J, Mitchell AJ, Wales J, Nielsen S. Mortality rates in patients with anorexia nervosa and other eating disorders: a metaanalysis of 36 studies. Arch Gen Psychiatry. (2011) 68:724-31. doi: 10.1001/archgenpsychiatry.2011.74

8. Huas C, Godart N, Caille A, Pham-Scottez A, Foulon C, Divac SM, et al. Mortality and its predictors in severe bulimia nervosa patients. Eur Eat Disord Rev. (2013) 21:15-9. doi: 10.1002/erv.2178

9. Franko DL, Tabri N, Keshaviah A, Murray HB, Herzog DB, Thomas JJ, et al. Predictors of long-term recovery in anorexia nervosa and bulimia nervosa: data from a 22-year longitudinal study. J Psychiatr Res. (2018) 96:183-8. doi: 10.1016/j.jpsychires.2017.10.008

10. Preti A, Rocchi MB, Sisti D, Camboni MV, Miotto P. A comprehensive metaanalysis of the risk of suicide in eating disorders. Acta Psychiatr. Scand. (2011) 124:6-17. doi: 10.1111/j.1600-0447.2010.01641.x institutional requirements. The patients/participants provided their written informed consent to participate in this study. Written informed consent was obtained from the individual(s) for the publication of any potentially identifiable images or data included in this article.

\section{AUTHOR CONTRIBUTIONS}

PH-B assessed, treated, and followed-up with the patient. AR interviewed the patient, conceptualized the case report, drafted the manuscript, and developed all figures. LKJ and SC contributed to the literature review and assisted with manuscript preparation. LG, QT, and MR provided substantial contributions to the interpretation of data as well as manuscript revisions. All authors have read and approved the final manuscript.

\section{ACKNOWLEDGMENTS}

We thank Dr. Andrew Petersen, the lead physician on this case, for his contributions to this study and continued innovation in the field.

11. Cucchi A, Ryan D, Konstantakopoulos G, Stroumpa S, Kaçar AS, Renshaw $S$, et al. Lifetime prevalence of non-suicidal self-injury in patients with eating disorders: a systematic review and meta-analysis. Psychol Med. (2016) 46:1345-58. doi: 10.1017/S0033291716000027

12. Mitchell JE, Agras S, Wonderlich S. Treatment of bulimia nervosa: where are we and where are we going? Int J Eat Disord. (2007) 40:95-101. doi: 10.1002/eat.20343

13. Vocks S, Tuschen-Caffier B, Pietrowsky R, Rustenbach SJ, Kersting A, Herpertz S. Meta-analysis of the effectiveness of psychological and pharmacological treatments for binge eating disorder. Int J Eat Disord. (2010) 43:205-17. doi: 10.1002/eat.20696

14. Wonderlich S, Mitchell JE, Crosby RD, Myers TC, Kadlec K, LaHaise K, et al. Minimizing and treating chronicity in the eating disorders: a clinical overview. Int J Eat Disord. (2012) 45:467-75. doi: 10.1002/eat.20978

15. Eddy KT, Tabri N, Thomas JJ, Murray HB, Keshaviah A, Hastings E, et al. Recovery from anorexia nervosa and bulimia nervosa at 22-year follow-up. $J$ Clin Psychiatry. (2017) 78:184-9. doi: 10.4088/JCP.15m10393

16. Steinhausen HC, Weber S. The outcome of bulimia nervosa: findings from one-quarter century of research. Am J Psychiatry. (2009) 166:1331-41. doi: 10.1176/appi.ajp.2009.09040582

17. Westmoreland P, Mehler PS. Caring for patients with severe and enduring eating disorders (SEED): certification, harm reduction, palliative care, and the question of futility. J Psychiatr Pract. (2016) 22:313-20. doi: 10.1097/PRA.0000000000000160

18. Strand M, Sjöstrand M, Lindblad A. A palliative care approach in psychiatry: clinical implications. BMC Med Ethics. (2020) 21:29. doi: 10.1186/s12910-020-00472-8

19. Park LT, Falodun TB, Zarate CA Jr. Ketamine for treatment-resistant mood disorders. Focus. (2019) 17:8-12. doi: 10.1176/appi.focus.20180030

20. Wilkinson ST, Sanacora G. A new generation of antidepressants: an update on the pharmaceutical pipeline for novel and rapid-acting therapeutics in mood disorders based on glutamate/GABA neurotransmitter systems. Drug Discov Today. (2019) 24:606-15. doi: 10.1016/j.drudis.2018.11.007

21. Berman RM, Cappiello A, Anand A, Oren DA, Heninger GR, Charney DS, et al. Antidepressant effects of ketamine in depressed patients. Biol Psychiatry. (2000) 47:351-4. doi: 10.1016/S0006-3223(99)00230-9 
22. Zarate CA, Singh JB, Carlson PJ, Brutsche NE, Ameli R, Luckenbaugh $\mathrm{DA}$, et al. A randomized trial of an N-methyl-D-aspartate antagonist in treatment-resistant major depression. Arch Gen Psychiatry. (2006) 63:856-64. doi: 10.1001/archpsyc.63.8.856

23. Diazgranados N, Ibrahim L, Brutsche NE, Newberg A, Kronstein P, Khalife $\mathrm{S}$, et al. A randomized add-on trial of an N-methyl-D-aspartate antagonist in treatment-resistant bipolar depression. Arch Gen Psychiatry. (2010) 67:793802. doi: 10.1001/archgenpsychiatry.2010.90

24. Zarate CA Jr., Brutsche NE, Ibrahim L, Franco-Chaves J, Diazgranados N, Cravchik A, et al. Replication of ketamine's antidepressant efficacy in bipolar depression: a randomized controlled add-on trial. Biol Psychiatry. (2012) 71:939-46. doi: 10.1016/j.biopsych.2011.12.010

25. Murrough JW, Iosifescu DV, Chang LC, Al Jurdi RK, Green CE, Perez $\mathrm{AM}$, et al. Antidepressant efficacy of ketamine in treatment-resistant major depression: a two-site randomized controlled trial. Am J Psychiatry. (2013) 170:1134-42. doi: 10.1176/appi.ajp.2013.13030392

26. Lapidus KA, Levitch CF, Perez AM, Brallier JW, Parides MK, Soleimani L, et al. A randomized controlled trial of intranasal ketamine in major depressive disorder. Biol Psychiatry. (2014) 76:970-6. doi: 10.1016/j.biopsych.2014. 03.026

27. Lai R, Katalinic N, Glue P, Somogyi AA, Mitchell PB, Leyden J, et al. Pilot dose-response trial of iv ketamine in treatment-resistant depression. World J Biol Psychiatry. (2014) 15:579-84. doi: 10.3109/15622975.2014.922697

28. Marcantoni WS, Akoumba BS, Wassef M, Mayrand J, Lai H, RichardDevantoy S. et al. A systematic review and meta-analysis of the efficacy of intravenous ketamine infusion for treatment resistant depression: January 2009-January 2019. J Affect Disord. (2020) 277:831-41. doi: 10.1016/j.jad.2020.09.007

29. Krupitsky EM, Grinenko AY. Ketamine psychedelic therapy (KPT): a review of the results of ten years of research. J Psychoactive Drugs. (1997) 29:165-83. doi: 10.1080/02791072.1997.10400185

30. Kolp E, Young MS, Friedman H, Krupitsky E, Jansen K, O'Connor L. Ketamine-enhanced psychotherapy: preliminary clinical observations on its effects in treating death anxiety. Int J Transpers Stud. (2007) 26:1-7. doi: 10.24972/ijts.2007.26.1.1

31. Calabrese L. Titrated serial ketamine infusions stop outpatient suicidality and avert ER visits and hospitalizations. Int J Psychiatr Res. (2019) 2:1-2. Available online at: http://scivisionpub.com/pdfs/titrated-serial-ketamine-infusionsstop-outpatient-suicidality-and-avert-er-visits-and-hospitalizations-918.pdf

32. Dore J, Turnipseed B, Dwyer S, Turnipseed A, Andries J, Ascani G, et al. Ketamine assisted psychotherapy (KAP): patient demographics, clinical data and outcomes in three large practices administering ketamine with psychotherapy. J Psychoactive Drugs. (2019) 51:189-98. doi: 10.1080/02791072.2019.1587556

33. Wheeler SW, Dyer NL. A systematic review of psychedelic-assisted psychotherapy for mental health: an evaluation of the current wave of research and suggestions for the future. Psychol Conscious. (2020) 7:279. doi: $10.1037 / \mathrm{cns} 0000237$

34. Halstead M, Reed S, Krause R, Williams MT. Ketamine-assisted psychotherapy for PTSD related to racial discrimination. J Clin Case Stud. (2021) 20:310-30. doi: 10.1177/1534650121990894

35. Mills IH, Park GR, Manara AR, Merriman RJ. Treatment of compulsive behaviour in eating disorders with intermittent ketamine infusions. QJM. (1998) 91:493-503. doi: 10.1093/qjmed/91.7.493

36. Dechant E, Boyle B, Ross RA. Ketamine in a patient with comorbid anorexia and MDD. J Women's Health Dev. (2020) 3:373-5. doi: 10.26502/fjwhd.2644-28840044

37. Scolnick B, Zupec-Kania B, Calabrese L, Aoki C, Hildebrandt T. Remission from chronic anorexia nervosa with ketogenic diet and ketamine: case report. Front Psychiatry. (2020) 11:763. doi: 10.3389/fpsyt.2020.00763

38. Schwartz T, Trunko ME, Feifel D, Lopez E, Peterson D, Frank GK, et al. A longitudinal case series of IM ketamine for patients with severe and enduring eating disorders and comorbid treatment-resistant depression. Clin Case Rep. (2021) 9:e03869. doi: 10.1002/ccr3.3869

39. Gagnier J, Kienle G, Altman DG, Moher D, Sox H, Riley DS, et al. The CARE guidelines: consensus-based clinical case report guideline development. J Clin Epidemiol. (2013) 67:46-51. doi: 10.1111/head.12246
40. Fairburn CG, Cooper Z, O'Connor M. The eating disorder examination. Int J Eat Disord. (1993) 6:1-8.

41. Fairburn CG, Cooper Z, O'Connor M. Eating Disorder Examination (Edition 16.0 D). In: Fairburn CG, editor. Cognitive Behavior Therapy and Eating Disorders. New York, NY: Guilford Press (2008). p. 265-308.

42. Nitsch A, Dlugosz H, Gibson D, Mehler PS. Medical complications of bulimia nervosa. Clevel Clin J Med. (2021) 88:333-43. doi: 10.3949/ccjm.88a.20168

43. Andrade C. Ketamine for depression, 4: in what dose, at what rate, by what route, for how long, and at what frequency? J Clin Psychiatry. (2017) 78:e852-7. doi: 10.4088/JCP.17f11738

44. Peyrovian B, McIntyre RS, Phan L, Lui LM, Gill H, Majeed A, et al. Registered clinical trials investigating ketamine for psychiatric disorders. J Psychiatr Res. (2020) 127:1-2. doi: 10.1016/j.jpsychires.2020.03.020

45. Murrough JW, Perez AM, Pillemer S, Stern J, Parides MK, aan het Rot M, et al. Rapid and longer-term antidepressant effects of repeated ketamine infusions in treatment-resistant major depression. Biol Psychiatry. (2013) 74:250-6. doi: 10.1016/j.biopsych.2012.06.022

46. Albott CS, Lim KO, Forbes MK, Erbes C, Tye SJ, Grabowski JG, et al. Efficacy, safety, and durability of repeated ketamine infusions for comorbid posttraumatic stress disorder and treatment-resistant depression. J Clin Psychiatry. (2018) 79:17m11634. doi: 10.4088/JCP.17m 11634

47. Phillips JL, Norris S, Talbot J, Birmingham M, Hatchard T, Ortiz A, et al. Single, repeated, and maintenance ketamine infusions for treatment-resistant depression: a randomized controlled trial. Am J Psychiatry. (2019) 176:401-9. doi: 10.1176/appi.ajp.2018.18070834

48. Krystal JH, Abdallah CG, Sanacora G, Charney DS, Duman RS. Ketamine: a paradigm shift for depression research and treatment. Neuron. (2019) 101:774-8. doi: 10.1016/j.neuron.2019.02.005

49. McGhee LL, Maani CV, Garza TH, Gaylord KM, Black IH. The correlation between ketamine and posttraumatic stress disorder in burned service members. J Trauma Acute Care Surg. (2008) 64:S195-9. doi: 10.1097/TA.0b013e318160bald

50. Feder A, Parides MK, Murrough JW, Perez AM, Morgan JE, Saxena S, et al. Efficacy of intravenous ketamine for treatment of chronic posttraumatic stress disorder: a randomized clinical trial. JAMA Psychiatry. (2014) 71:681-8. doi: 10.1001/jamapsychiatry.2014.62

51. Feder A, Rutter SB, Schiller D, Charney DS. The emergence of ketamine as a novel treatment for posttraumatic stress disorder. Adv Pharmacol. (2020) 89:261-86. doi: 10.1016/bs.apha.2020.05.004

52. aan het Rot M, Collins KA, Murrough JW, Perez AM, Reich DL, Charney DS, et al. Safety and efficacy of repeated-dose intravenous ketamine for treatment-resistant depression. Biol Psychiatry. (2010) 67:13945. doi: 10.1016/j.biopsych.2009.08.038

53. Newport DJ, Carpenter LL, McDonald WM, Potash JB, Tohen M, Nemeroff $\mathrm{CB}$, et al. Ketamine and other NMDA antagonists: early clinical trials and possible mechanisms in depression. Am J Psychiatry. (2015) 172:950-66. doi: 10.1176/appi.ajp.2015.15040465

Conflict of Interest: The authors declare that the research was conducted in the absence of any commercial or financial relationships that could be construed as a potential conflict of interest.

Publisher's Note: All claims expressed in this article are solely those of the authors and do not necessarily represent those of their affiliated organizations, or those of the publisher, the editors and the reviewers. Any product that may be evaluated in this article, or claim that may be made by its manufacturer, is not guaranteed or endorsed by the publisher.

Copyright (C) 2021 Ragnhildstveit, Jackson, Cunningham, Good, Tanner, Roughan and Henrie-Barrus. This is an open-access article distributed under the terms of the Creative Commons Attribution License (CC BY). The use, distribution or reproduction in other forums is permitted, provided the original author(s) and the copyright owner(s) are credited and that the original publication in this journal is cited, in accordance with accepted academic practice. No use, distribution or reproduction is permitted which does not comply with these terms. 